\title{
CORPOS DISSIDENTES, SAÚDE SEXUAL E MICROBIOPOLÍTICAS DE RESISTÊNCIA NA AMAZÔNIA ATLÂNTICA
}

\author{
QUEER BODIES, SEXUAL HEALTH AND THE \\ MICRO-BIOPOLITICS OF RESISTANCE IN THE \\ BRAZILIAN AMAZON
}

\author{
José Sena*
}

\section{RESUMO}

Este trabalho tem por objetivo analisar as disputas metapragmáticas sobre o cuidado em saúde sexual estabelecidas na relação entre uma biopolítica oficial e as práticas de cuidado em saúde de corpos dissidentes no território da Amazônia Atlântica contemporânea. Ao examinar discursos oficiais, como os presentes no Plano Nacional de Saúde Integral LGBT (BRASIL, 2013), assim como a efetiva operacionalização de princípios da Promoção à Saúde (AYRES, PAIVA; FRANÇA JÚNIOR, 2012), a pesquisa detecta o funcionamento de uma política de silenciamento e precarização das demandas da saúde sexual LGBTI+ no contexto local, a qual é confrontada por estratégias microbiopolíticas de resistência. Para realizar o estudo, foi desenvolvido um trabalho etnográfico (PEIRANO, 2008; 2014) ao longo dos anos de 2016-2019, com jovens LGBTI+ no contexto de festas, afterparties e convivências domésticas em repúblicas estudantis na região dos Caetés. Fundamentado pelas teorizações sobre biopolítica (FOUCAULT, 1999) e performatividade (BUTLER, 2004), o foco analítico centra-se nas performances narrativas (MOITA LOPES, 2006) encenadas por sujeitos LGBTI+, as quais encenam disputas metapragmáticas (SILVERSTEIN, 1998) em torno do discurso oficial do Estado, criticando o lugar que este relega à promoção do cuidado em saúde sexual da população LGBTI+. Conclui-se que as práticas de resistências microbiopolíticas identificadas nas experiências sociais locais questionam o discurso oficial e a manutenção de um regime LGBTfóbico.

Palavras-chave: vulnerabilidade em saúde; LGBTI+; performatividade; metapragmática biopolítica; Amazônia.

\section{ABSTRACT}

This article aims at analyzing the metapragmatic disputes over healthcare between the official State biopolitics and the actual healthcare practices of queer bodies in the current Brazilian Amazon. By examining official discourses, such as the ones found in the National LGBT Whole Health Plan [Plano Nacional de Saúde Integral LGBT] (BRASIL, 2013), as well

\footnotetext{
* Universidade Federal do Rio de Janeiro, UFRJ, Rio de Janeiro, RJ, Brasil. senaufrj@gmail.com Orcid: https://orcid.org/0000-0003-4422-8800

Agradeço ao CNPq pela bolsa de doutorado que possibilitou esta pesquisa (CNPq 141379/2016-2).

Agradeço a Daniel de Augustinis pela leitura crítica da primeira versão do texto
} 
as the effective operationalization of Health Promotion principles (AYRES; PAIVA; FRANCE JÚNIOR, 2012), the research detects the functioning of a policy of silencing and precarious demands of sexual health LGBTI + in the local context, which is confronted by microbiopolitical strategies of resistance. In order to meet this objective, an ethnographic study was conducted (PEIRANO, 2008; 2014) between 2016 and 2019 with LGBTI+ youth, in the context of parties, smaller reunion staking place right after a major party (so called 'afterparties' in Portuguese) and daily interactions in student shared homes in the Brazilian Amazon, in the interior of the country. Based on theories about biopolitics and performativity (FOUCAULT, 1999; BUTLER, 2004), the analytical focus is centered on narrative performances (MOITA LOPES, 2006) staged by LGBTI + subjects, such as which mobilize metapragmatic disputes (SILVERSTEIN, 1998) around the official state discourse, criticizing the place it relegates to the promotion of sexual health care for the LGBTI + population. It concludes that the practices of resistance in the context of precarious sexual health among LGBTI+ individuals who were identified in the situated social experiences analyzed in this article question the official biopolitics and the maintenance of the LGBTphobic current regime.

Keywords: health vulnerability; LGBTI+; performativity; metapragmatics; biopolitics; Brazilian Amazon.

\section{INTRODUÇÃO}

Qual o lugar apropriado para nossa indignação? As artes, a disputa de leis, as manifestações de rua, a escrita? Onde devemos jogar nossas energias, nosso tempo, nossas entranbas? Devemos bierarquizar as dores, as exclusões? Como sentir como minha a dor do outro? Como transformar a alteridade, cantada em versos e prosas pelas Ciências Humanas, em ação política?

Berenice Bento, 2015, p. 13.

Em 2021, a Política Nacional de Saúde Integral LGBT (BRASIL, 2013), prevista no âmbito do Sistema Único de Saúde (SUS, doravante), completa 10 anos. À margem dessa política, as vidas dissidentes do território da Amazônia Atlântica ${ }^{1}$ têm sofrido os efeitos de uma política de "deixar morrer" (FOUCAULT, 1999, p. 287) que se estrutura historicamente na articulação entre diferentes domínios ideológicos, como a heteronormatividade e a cisgeneridade compulsórias, o machismo, a LGBTfobia, a moralidade dogmática judaico-cristã e a colonialidade territorial endógena ${ }^{2}$, que orientam discursos, práticas e visões de

1. A Amazônia Atlântica, composta por 49 municípios, é dividida em três regiões: a Guamá, a Capim e a Caeté (BRITO; SARAIVA; SILVA, 2019). Tenho me esforçado em utilizar os nomes que caracterizam as diferentes regiões da Amazônia no intento de confrontar a generalização colonizadora e subalternizante que historicamente insiste em apagar a diversidade humana, cultural, política, socioeconômica desse vasto território (ver SENA, 2020a).

2. Com base no entendimento de que a colonialidade, enquanto sistema de dominação ocidental, ganha dimensões regionais, argumento que no Brasil há historicamente um processo de colonização 
mundo de importantes instituições sociais como a família, a religião e o Estado, este último por meio da escola, da saúde pública, dentre outras instituições.

É possível afirmar que uma bio-necropolítica (LIMA, 2018) tem sido posta em prática por meio de processos discursivos de silenciamento e precarização dos modos de vida de pessoas dissidentes. Se as LGBTfobias na infância e na adolescência dentro de casa, na escola e na igreja incidem sobre a autoestima dessas pessoas, para mencionar apenas alguns dos espaços em que o preconceito é criado, sustentado e estranhado, a situação se agrava no âmbito das instituições de saúde as quais perpetuam uma política de morte quando negam (ou ignoram a existência das demandas de) orientação, atendimento e acompanhamento no cuidado em saúde específico para a população $\mathrm{LGBTI}+{ }^{3}$. Essa situação ganha peculiaridades quando se trata da região norte brasileira.

Um exemplo flagrante dessa realidade foi o modo como o governo brasileiro conduziu as políticas de saúde no território amazônico no contexto de emergência do HIV/aids, assistindo-o somente quando a epidemia já estava estabilizada no restante do país (LAURINDO-TEODORESCU; TEIXEIRA, 2015). Esta constatação é relevante quando comparada aos dados que mostram que a mortalidade pela epidemia do HIV na região norte manteve-se acima da média em comparação às demais regiões do país até a primeira década dos anos 2000 (REIS; SANTOS; CRUZ, 2007), dados que se repetem nesta quarta década de existência do HIV/aids (BRASIL, 2019).

Apesar desse grave contexto, estratégias microbiopolíticas de resistência têm sido engendradas de dentro da estrutura que busca produzir essas subjetividades como abjetas, em que modos de vida, de práticas sexuais e de cuidado em saúde sexual de sujeitos LGBTI+ confrontam a política de deixar morrer prevista pela biopolítica oficial.

Atento às alternativas sociais que emergem desses contextos de abjeção, a presente pesquisa adota uma abordagem Indisciplinar (MOITA LOPES, 2006/2016) e Contra-colonial (SANTOS, 2015), posicionando uma postura ética que investe em uma proximidade crítica nos estudos da linguagem (MOITA LOPES; FABRÍCIO,

endógena das regiões centrais, especialmente o sudeste, diante da Amazônia. Os efeitos desse processo se fazem sentir nas práticas micro e macro políticas que generalizam, silenciam, exotizam e produtificam saberes, culturas e riquezas naturais perpetuando a lógica colonial, racista e neoliberal do norte global. O caso das políticas de saúde no contexto da covid-19 para as populações tradicionais indígenas e quilombolas da Amazônia é um exemplo atual da colonialidade bio-necropolítica do Estado brasileiro.

3. O Manual de Comunicação lançado em 2018, pela Aliança Nacional LGBTI e pela GayLatino, recomenda o uso da sigla LGBTI+. O símbolo + foi acrescentado à sigla LGBTI para abranger outras orientações sexuais, identidades e expressões de gênero. 
2019). Apostando em uma abordagem etnográfica (PEIRANO, 2008; 2014; JUNG; SILVA; SANTOS, 2019), me posiciono como um pesquisador radicalmente in-mundo (ABRAÃO, 2013; SENA, 2020a) e construo a pesquisa com base em uma tripla articulação: pesquisador, sujeito LGBTI+ e ativista local ${ }^{4}$. Argumento com Calazans, Pinheiro e Ayres (2018, p. 287) que,

compreender a dinâmica dos processos envolvidos nesse diálogo possibilita vislumbrar o reconhecimento dos militantes dos movimentos sociais e de integrantes dos próprios grupos implicados - gays e outros $\mathrm{HSH}^{5}$, bem como travestis, transexuais femininos, PS, UDI etc. como partícipes na construção das políticas.

Essa prática metodológica-ético-política tornou-se possível pelo apoio coletivo da população LGBTI+ local, em diferentes cidades da região dos Caetés, que não apenas consentiram em colaborar com o estudo, por meio do Termo de Consentimento Livre e Esclarecido (TCLE), mas assumiram coletivamente a importância desse debate e ação microbiopolítica para pautar nossas demandas de vida no âmbito da saúde sexual. Essa perspectiva vai ao encontro da argumentação de Paul Preciado, quando afirma que, ao produzir conhecimento, é necessário

"criar condições de enunciação" através das quais "os prisioneiros", "as associações de vizinhos" ou "homossexuais" possam produzir um saber sobre si mesmos, se reapropriando das tecnologias de poder que lhes constituem como abjetos (PRECIADO, 2019, p. 32, grifo meu).

Avançando na produção de saberes "sobre o outro", para a produção de saberes "sobre nós" e/ou "com o outro", a pesquisa investe em uma visada performativa da linguagem (BUTLER, 2004), associada a uma perspectiva indexical (SILVERSTEIN, 1998 ; 2003), em que a linguagem protagoniza não apenas os processos de produção de significados no mundo social, mas ela mesma é constitutiva e, portanto, produz a vida social (MOITA LOPES, 2006/2016; FABRICIO, 2006; SENA, 2020b).

Fundamentalmente, a perspectiva performativa butleriana argumenta que o gênero e o corpo são efeitos de práticas e discursos que decorrem de produções políticas, históricas e culturais engendradas por uma matriz de inteligibilidade específica. No caso, o modo como temos produzido o domínio sexo-generificado na sociedade contemporânea é efeito de processos complexos de repetição e saturação de normas sociais orientadas pela visão de mundo cisgênera, heteronormativa,

4. Além de sujeito LGBTI+ amazônida, sou membro-fundador do coletivo CABOKA e do Coletivo Curupiranhas do Pará, na Amazônia Atlântica.

5. HSH, segundo literatura biomédica, é sigla para Homens que fazem sexo com homens, no intento de contemplar homens que não se identificam como parte da cultura gay, mas eventualmente mantém relações sexuais com outros homens. Para aprofundar esta reflexão ver Mora, Brigeiro e Monteiro (2018). 
judaico-cristã, falocêntrica e colonial, que tem se imposto como a única alternativa verdadeira e, portanto, hegemônica. É assim que ela tem produzido discursivamente como marginais aqueles/as que não se adéquam a sua norma. Entretanto, mesmo dentro desse regime de coação altamente estruturado, é possível confrontá-lo de dentro do seu próprio funcionamento que não resiste à mudança contínua da história e da cultura, e que tem seus efeitos materiais nos corpos e modos de vida dos sujeitos.

A visão performativa que orienta o presente debate é fruto dos cruzamentos filosóficos mobilizados por Butler, o que inclui, por exemplo, a teoria dos atos de fala de John Austin (1990), a visão desconstrucionista de Jacques Derrida (1973; 1991), e as reflexões focaultianas sobre o funcionamento da biopolítica/biopoder e das relações de saber-poder-subjetividade (FOUCAULT, 1999). É com base nessa perspectiva que tenho argumentado pelo protagonismo da linguagem (SENA, 2020b) nas práticas sociais, me aliando a uma visada não essencialista e pragmática nos estudos da linguagem (MARTINS, 2004; SILVERSTEIN, 1998; 2003).

Com base nessa visada teórica, busco produzir alguma inteligibilidade sobre como jovens $\mathrm{LGBTI}+$, especificamente, gays $/ \mathrm{HSH}$, produzem metapragmáticas ${ }^{6}$ e práticas sexo-generificadas no contexto biopolítico da Amazônia Atlântica contemporânea e sobre como suas performances ${ }^{7}$ narrativas (HYDEN et al., 2014) ratificam ou confrontam a metapragmática oficial sobre sujeitos, corpos e práticas de cuidado em saúde sexual. Para tanto, uma etnografia participante (PEIRANO, 2008; SENA, 2018; 2020a) foi realizada em afterparties nas repúblicas estudantis da região dos Caetés junto a jovens LGBTI+, a maioria estudantes universitários.

Para empreender esse debate, as notas geradas em campo se somaram aos dados produzidos na pesquisa com os documentos oficiais, as notícias em circulação na mídia e as narrativas produzidas em entrevistas com os sujeitos participantes do estudo. Mobilizando esses textos/discursos, selecionei uma das experiências etnografadas como foco, embora, eventualmente, recorra a outras informações geradas em campo. Nesse sentido, o texto está organizado em dois momentos: 1)

6. Conforme aprofundo na seção 1, metapragmática diz respeito a como as pessoas refletem sobre suas práticas de produção de significados no mundo social, processo que se dá na linguagem e com a linguagem.

7. Enquanto a performance em Butler é orientada por uma visão austiniana e derridiana de performatividade para entender como (des)fazemos gênero, Bauman e Briggs, operando a partir do campo da Antropologia Linguística, "usam o conceito de performance para se referir a eventos narrativos que são diferentes de outros eventos comunicativos porque envolvem performances artísticas (a função expressiva ou poética da prática narrativa)" (GUIMARÃES; MOITA LOPES, 2018, p. 36). Opero com essas duas noções nesta pesquisa. 
Contextualização do campo biopolítico, metodológico e analítico; 2) Análise das disputas metapragmáticas sobre cuidado em saúde sexual LGBTI+.

\section{CONTEXTUALIZANDO O CAMPO BIOPOLÍTICO, METODOLÓGICO E ANALÍTICO}

Pautar a temática do cuidado em saúde sexual nunca foi uma tarefa fácil para pessoas LGBTI+. Seja pelo repertório político que incide sobre nossos corpos em decorrência da pandemia do HIV/aids, seja pela LGBTfobia estrutural aliada ao machismo que tem orientado por séculos o modo de funcionamento de diferentes instituições sociais (BRASIL, 2015). Essa constatação é hierarquizada a depender do território político em que se encontram os diferentes sujeitos do gênero/ sexualidades. Esse entendimento passou a ser aprofundado logo que iniciei a pesquisa de campo em 2016, quando fui interpelado a procurar um Centro Especializado ${ }^{8}$ ( $\mathrm{CE}$, doravante) para realizar exames em uma cidade da Amazônia Atlântica, após viver uma relação sexual sem preservativo. Depois dessa experiência, que me levou a constituir as primeiras anotações de meu diário de campo, me chamou atenção os modos como as práticas sexuais e de cuidado em saúde eram vividas no contexto local, com ênfase na população LGBTI+ e suas relações com instituições como a família, a escola e os serviços de saúde.

A área urbana da cidade de Bragança do Pará foi o território em foco nesta pesquisa. Conhecida como a pérola do Caeté, fazendo referência ao seu ancestral Tupinambá (ALENCAR, 2014), é famosa por se constituir como uma cidade Universitária, a qual atende a diferentes estudantes, entre quilombolas, indígenas, cabokas $^{9}$ moradores da zona rural e urbana das variadas cidades da região. Sendo uma das 15 cidades que compõem a região dos Caetés (BRITO; SARAIVA; SILVA, 2019) na Amazônia Atlântica, Bragança é uma cidade de 406 anos e uma população aproximada de 127 mil habitantes, segundo dados do IBGE ${ }^{10}$.

$\mathrm{Na}$ base da economia é possível identificar como importantes atividades o extrativismo (vegetal e animal), a agropecuária/agricultura, a pecuária e o turismo (CORDEIRO; ARBAGE; SCHUWARTZ, 2017; BRITO; SARAIVA; SILVA, 2019). A cidade é famosa pelas festividades culturais e religiosas, como a Marujada de São Benedito e o festival junino, mas também se destaca por constituir uma

8. Chamarei Centros Especializados fazendo referência às instituições de saúde pública como hospitais, postos de saúde, Centros de Testagem e Aconselhamento (CTA) etc.

9. Termo êmico utilizado em cidades médias e pequenas da Amazônia Atlântica que se refere aos povos racializados em cruzo, sobretudo, negros e indígenas.

10. Disponível em: https://cidades.ibge.gov.br/brasil/pa/braganca/panorama Acesso em: 07.11.2019. 
região de praias e igarapés. A circulação de pessoas LGBTI+ é grande, sobretudo se considerarmos as cidades vizinhas, Viseu, Augusto Corrêa, Tracuateua, Salinas e Capanema, dentre outras, com as quais Bragança mantém um fluxo constante de pessoas. Esse fluxo aumenta no período das festividades, notadamente nos meses de junho, julho e dezembro.

É importante destacar ainda que, devido às festividades da região serem, em sua maioria, de natureza religiosa, isso produz um contexto fortemente atravessado por discursos e princípios de base judaico-cristã. Assim, embora a região dos Caetés constitua uma diversidade religiosa com terreiros de umbanda e práticas de curandeiras, parteiras, bezendeiras e pajés, vive sob o forte domínio das igrejas católica e evangélica. É nesse cenário que uma cultura e territorialidade ${ }^{11}$ cisheteronomativa, patriarcal e dogmático-religiosa impõe regimes de verdade e biopolíticas que produzem espaços de abjeção para populações dissidentes.

A biopolítica/biopoder ${ }^{12}$, entendida como uma política de regulamentação e exercício de poder sobre a vida, é um conceito cunhado por Foucault $(1999 ;$ 2000; 2008) para identificar como as estratégias de governança passam de um domínio macropolítico, para uma dimensão micropolítica. A regulação da vida passa a estar atrelada à produtividade capitalista que incide sobre os corpos e modos de vida das populações, com vistas a maximizar a vida: docilizá-la e torná-la mais produtiva, enfim, discipliná-la.

A complexidade do conceito de biopolítica se configura precisamente pela capacidade de coexistência de significações e discursos que, mesmo operando em diferentes instituições sociais, erguem um regime de poder que se exerce sobre os corpos e as populações (pensados como extremos de um continuum). O poder se espraia pelas instituições sociais, como, por exemplo, o CE, organizando e demandando a obediência de seus alvos ao mesmo tempo em que produz uma constelação de saberes que distingue entre sujeitos higiênicos e doentes, civilizados e bárbaros, modernos e pré-modernos. É assim que saber-poder-subjetividade se

11. Embora mencione a questão do território/territorialidade, não o aprofundarei neste texto. De todo modo, é importante enfatizar que enquanto o conceito de território está fortemente vinculado ao de espaço, o que agrega uma noção de fixidez, mesmo em termos políticos, o de territorialidade ganha um caráter mais dinâmico, pois ela é constituída em relações e práticas sociais de pertencimento. Você pode pertencer a um território simplesmente por estar inserido no contexto espacial ou político dele, diferentemente da territorialidade, a qual solicita sua participação ativa, exige que você aja, e ao agir, produza condições de existência dessa territorialidade. Territorializar o espaço, conforme Raffestin (1993), é ocupá-lo de signos, significações, sujeitos e práticas. É produzi-lo inscrito em relações de saber-poder-subjetividade (ver SENA, 2020a).

12. Ora utilizada de modo distinto, ora como sinônimos nas teorizações de Foucault, a biopolítica diz respeito à regulamentação da vida, enquanto o biopoder corresponde ao impacto do poder político sobre a vida. 
entrelaçam. Com efeito, é assim que Foucault pensa a subjetividade: um sujeito que obedece para que então possa ser livre. Como Foucault (2008) explica em Segurança, Território, População, o poder disciplinar moderno não age sobre a população em sua totalidade, mas produz cálculos estatísticos capazes de prever condutas de risco antes mesmo de elas acontecerem, inserindo o poder disciplinar em uma "média que vai ser considerada, digamos, ótima" (p. 8). É por meio dessa complexa relação entre disciplina e liberdade que se realiza a governança sobre subjetividades e a legitimação de verdades que se materializam em modelos metapragmáticos oficiais. Torna-se possível argumentar, então, que os entendimentos e práticas de cuidado em saúde sexual, enraizados em processos sócio-históricos específicos, são construídos com base nas demandas políticas das quais participam as diferentes instituições sociais articuladas ao Estado.

Foi investindo nesse entendimento que imergi, ao longo de 12 meses, em contextos de festas, afterparties e convivências domésticas em repúblicas estudantis na região dos Caetés. Ao proceder em alguns momentos com a Observação Participante (CLIFFORD, 2002), reuni em notas de campo entendimentos e discursos sobre as práticas sexuais e de cuidado em saúde sexual LGBTI+. Com a implicação do meu corpo na pesquisa, adotei a Participação Observante (PERUZZO, 2017) usando uma aproximação tática ou reflexiva, pois as experiências convividas e partilhadas também incidiam sobre meu corpo, meu desejo e meu prazer (SENA, 2018).

Essa reflexão é crucial para a construção do meu engajamento como um pesquisador radicalmente in-mundo, o que implica uma agenda política a qual orientou os caminhos da pesquisa na reflexão sobre o direito à saúde sexual LGBTI+. Conforme Abraão et al. (2013), o pesquisador in-mundo não opera com a cisão paradigmática sujeito-objeto, mas pensa o sujeito pesquisador no mundo, como parte desse mundo. Indiferente a noções modernistas (BAUMAN; BRIGGS, 2003) como imparcialidade, neutralidade, "não contaminação", nessa perspectiva: "o pesquisador in-mundo emaranha-se, mistura-se, afeta-se com o processo de pesquisa, diluindo o próprio objeto, uma vez que se deixa contaminar com esse processo, e se sujando de mundo, é atravessado e inundado pelos encontros" (ABRAÃO, et al. 2013, p.157-158).

Baseado nesse entendimento é que construo a radicalidade do pesquisador inmundo na tríplice articulação entre ativista, sujeito e pesquisador, em que sou sujeito não apenas das práticas sociais dos LGBTI+ da região dos Caetés, mas de suas práticas sexuais e de cuidado em saúde sexual, em que vivo relações sexuais com tais sujeitos e compartilho experiências de prazer, desejo, medos, dúvidas, opressões e resistências. Argumento que me engajar em práticas sócio-sexuais das dissidências 
na Amazônia Atlântica é fundamental para a reflexão e enfrentamento de discursos e ações patologizantes, moralistas e sexistas no contexto local, assim como, para a ampliação do debate sobre a importância do nosso lugar político em democracias frágeis, como a brasileira.

É desse modo que uma abordagem pragmática ou indexical se torna chave para a análise e interpretação dessas práticas que envolvem ideologias, domínios axiológicos, relações de saber-poder. $\mathrm{O}$ signo indexical, conceito que nos ajuda na reflexão sobre a produção de contextos e significações, decorre das teorizações da semiótica de Charles Peirce, para quem o índice, é um signo que apresenta uma dimensão de contiguidade com o objeto que mobiliza, ou seja, está implicado em uma relação de causalidade e/ou de consequência entre signo e significado (PEIRCE, 1977). Isso implica dizer que ao mesmo tempo em que o signo indexical pressupõe seu contexto, tendo em vista a história de uso desse signo, ele produz seu contexto, pois o novo lugar que assume no tempo e no espaço, atualiza seu potencial de significação (SILVERSTEIN, 1998; 2003).

Com essa compreensão sob minha atenção, adotei as pistas indexicais (WORTHAM, 2001) ou índices linguísticos (SILVERSTEIN, 1998; 2003) como minhas principais ferramentas teórico-analíticas para identificar e interpretar as ações sociais dos sujeitos e suas metapragmáticas. Os índices linguísticos ou pistas indexicais podem ser lidos "como marcas linguísticas que sinalizam as ações semióticas dos participantes na interação" (MELO; MOITA LOPES, 2014, p. 661). Ao se reportarem a identificações sociais, visões de mundo, pessoas etc. participam dos processos de contextualização espaço-temporais envolvidos em dinâmicas interacionais (WORTHAM, 2001). Avaliações, qualificações, explicações etc. emergem das experiências no campo em estudo, em que pistas linguísticas ou signos presentes em tais acontecimentos mobilizam dimensões sócio-históricas, culturais e políticas mais amplas.

Segundo Silverstein, se a pragmática é a linguagem em uso, o universo semiótico em funcionamento, a metapragmática é a orientação do uso com base em demandas comunicativas e ideológicas específicas. Isso significar dizer que a pragmática é "enquadrada", "regimentada", "estipulada" metapragmaticamente (SILVERSTEIN, 1998; 2003; SILVA, 2014).

Antes de chegarmos às festas e afterparties, trazemos os repertórios sociais e afetivos que enquadram metapragmaticamente o que seja viver como um corpo dissidente, repertórios inscritos na linguagem e com a linguagem, estruturando limites e possibilidades para nossas existências. Nesse sentido, entender o (bio) 
poder nas suas ramificações mais locais e menos jurídicas mobiliza a centralidade da linguagem na produção desse processo.

\section{NA AFTERPARTY}

Antes de iniciar a análise, se faz fundamental posicionar alguns aspectos que contornam o contexto situado da pesquisa. Nas entrevistas realizadas com os diferentes sujeitos colaboradores deste estudo (2016-2019), e encaminhadas após as situações vividas em campo, como a narrada nesta seção, é importante enfatizar a presença de um forte discurso moralista religioso nas suas trajetórias de vida, sendo alguns de família evangélica e católica com relatos de LGBTfobia em casa e na escola. À exceção de $\mathrm{Caio}^{13}$ e de Ruii ${ }^{14}$, que tiveram alguma orientação familiar ou escolar no âmbito da sexualidade, ainda que hetero-orientada, os demais sujeitos foram furtados dessa orientação. Articulado ao discurso religioso, familiar e escolar, ao investigar a circulação de informações sobre cuidado em saúde sexual LGBTI+ por parte do governo local em sites e redes sociais de fácil acesso à população, e que deveria atender aos princípios previstos pela Nova Promoção à Saúde ${ }^{15}$ (AYRES; PAIVA; FRANÇA JR., 2012) e pela Política Nacional de Saúde Integral LGBT (BRASIL, 2013), não há registro de ações específicas para esse público ao longo da década atual. Inclusive a sigla LGBTI+ e variantes, com exceção de um único registro, nem comparecem nas ações municipais.

Essa precarização na educação e/ou orientação sexual desses jovens, que respondem à biopolítica oficial cisheteronormativa e LGBTfóbica (BRASIL, 2015) presente na Amazônia Atlântica contemporânea, trouxe, inclusive, consequências sobre seus corpos. Argumento que a performatividade dos silêncios produzidos discursivamente pela família, pela escola e pela saúde pública sobre cuidado em saúde sexual de vidas LGBTI+ produziu as condições de adoecimento desses

13. Todos os nomes nesta pesquisa, a exceção do meu, são fictícios no intento de preservar a identidade dos participantes do estudo.

14. Sujeito envolvido em outra prática sexual no campo etnográfico.

15. Destaco três princípios fundamentais e que incidem diretamente no presente estudo: "a Equidade, prevê a necessidade de reconhecimento das desigualdades implicadas nas atividades de saúde (gênero, sexualidades, raça, classe social, geração etc.) (...) a Participação Social [que] envolve a produção e circulação democrática da informação, oportunizando, assim, construções coletivas na relação entre setores institucionais da saúde e a população. [E] as condições de Empoderamento dos sujeitos (...) para que eles possam requerer direitos e participar como cidadãos frente às situações que ameaçam ou restringem sua condição de saúde" (SENA, 2020a, p. 83-84). Para aprofundar esse debate ver Sícoli e Nascimento (2003) e Ayres, Paiva e França Jr. (2012). 
sujeitos com Infecções Sexualmente Transmissíveis (IST) como HIV, Sífilis e HPV (SENA, 2018; 2020a).

Conforme veremos na seguinte análise, para além do adoecimento do corpo, "o adoecimento das visões de mundo" engendradas pela biopolítica oficial amplia o debate sobre gênero/sexualidades e o cuidado em saúde sexual de populações dissidentes.

Josét, Caio, Raul, Camila, André

A experiência em foco, ocorrida em uma terça-feira junina de 2017, mantém um roteiro similar às diferentes experiências convividas no campo etnográfico (SENA, 2020a). Era comum, antes das afterparties, passarmos por pelo menos dois dos seguintes locais da cidade: Benquerência, orla da cidade, posto de gasolina próximo à rodoviária, o Viúva Negra bar, o Chavecos, o bar do trevo ${ }^{17}$. As afterparties acontecem/ram nas repúblicas estudantis e geralmente são extensões das festas pela cidade.

Naquela noite, eu, Camila, Caio e Raul fomos surpreendidos, quando retornávamos para casa, por um boy "bonito em um padrão cisgênero branco"18 que nos abordou em uma das encruzas da avenida Souza Franco. André se mostrou animado para comprarmos mais bebida e seguirmos noite adentro, o que nos encaminhou para mais uma afterparty.

Amontoados na área estreita do lado de fora da casa, iniciamos nosso ritual dionisíaco que envolvia também a conquista do boy que decidiu passar a madrugada bebendo com quatro LGBTI+, sendo 3 bichas afeminadas, algo incomum e que chamou nossa atenção. Foi assim que reiniciamos a bebedeira, enquanto escutávamos música e conversávamos. Do diário de campo recupero a seguinte passagem:

Entre brincadeiras e risos, propomos o jogo do beijo. A brincadeira que era um pretexto mais que descarado para beijar André, consistia em fazer perguntas indiscretas um ao outro, uma versão de "verdade ou desafio"19. Caso a pessoa não quisesse responder, teria que beijar alguém do grupo sendo a escolha feita pela pessoa que estava fazendo a pergunta.

16. A exceção de mim, os demais sujeitos possuem idade entre 22 e 26 anos, sendo a maioria universitários.

17. Alguns dos locais mais frequentados por pessoas LGBTI+ da cidade.

18. Colocarei entre aspas trechos da narrativa produzida com base nas notas de campo, mantendo apenas os trechos mais significativos para as análises que irei operar em seguida.

19. Jogo muito frequente utilizado nas afterparties nesse contexto de pesquisa. O jogo consiste em um grupo de pessoas sentadas no chão dispostos em roda. No centro da roda, gira-se algum objeto com extremidades diferentes. Quando o objeto para de rodar, as extremidades, com significados previamente definidos, apontam quem irá executar e quem irá responder a interpelação "Verdade 
Ao entender a regra do jogo, André pediu para não participar e apenas assistir à brincadeira. Não sem a objeção de todos do grupo, o pedido de André acabou sendo aceito. Entrecortado a brincadeira e as perguntas que fazíamos uns aos outros, íamos conversando e conhecendo também o homem com quem flertávamos. (...) Foi nesse contexto, provavelmente sentindose à vontade, que André lança um questionamento que nos acalorou: "se eu tivesse transado com uma travesti, eu seria gay?". Visivelmente surpresos (...) tentamos explicar uns por cima dos outros alguns entendimentos sobre o que é ser um gay.

As performances narrativas de André nos davam pistas de como ele construía a si como homem cishetero diante da audiência que o escutava atentamente. Do mesmo modo, ele reagia as nossas performances. Entre as histórias narradas, André encenou poder, ao contar sobre aventuras e acidentes em que se envolveu e sobreviveu, assim como, sobre pessoas influentes no meio da venda de drogas que conhecia. Falou da mãe, muito religiosa, e do controle que exercia sobre ele. Foi após algum tempo de conversa que André revelou já ter transado como uma mulher travesti, conforme recupero do Diário de campo:

Foi, então, que no meio dos flertes e brincadeiras, ele revela que já havia transado com uma travesti. Essa afirmação instaurou um novo debate no grupo. André reforçava que sentiu atração por ela, pois "ela era igual a uma mulher de verdade" e que não a tinha beijado na boca...

Instaurando um novo debate no grupo, a performance narrativa de André projetava metapragmáticas sobre sua sexualidade e localizava índices de feminilidade enfatizada ${ }^{20}$ que o autorizaram a se engajar em uma relação sexual com uma mulher travesti. Esse diálogo nos aproximou ainda mais de André, o que o levou, algum tempo depois, a fazer a seguinte proposta:

André se aproxima e me diz no ouvido que queria transar com nós três (...) colocando algumas condições: que ninguém tocasse na bunda dele; que não ia ter beijo na boca; e que fizéssemos todos juntos. (...)

Esses excertos narrativos do diário de campo, que terá sequencia a seguir, foram construídos na área dos fundos da república enquanto o dia amanhecia. Logo após toda a situação vivida, liguei o computador e produzi longas anotações sobre tudo o que havia acontecido naquela madrugada, registrando cada detalhe de que pude me recordar. A feitura da narrativa sofreu alterações importantes, uma vez que a submeti ao olhar de pelo menos dois sujeitos envolvidos na situação. Para nos determos nas análises das performances que engendraram microbiopolíticas de

ou desafio?" Se a pessoa responder verdade, uma pergunta será direcionada a ela, se responder desafio, um desafio será lançado para que ela execute.

20. Conforme denominam Connell e Messerschmidt (2013). 
resistência no âmbito do cuidado em saúde sexual LGBTI+, é necessário chamar atenção para algumas disputas metapragmáticas sexo-generificadas que nos ajudam a ler as práticas de resistência em foco.

Primeiramente, é me posicionando em relação às performances corpóreodiscursivas de André que perspectivizo muitos dos lugares sociais em que me encontro, aqui e ali, nesse processo. Ao identificá-lo como branco e cisgênero, por exemplo, delimito uma diferenciação importante em relação a mim, assim como a Caio e a Raul, marcados racialmente com características negras e indígenas. Essa percepção se entrelaça às performances de masculinidade hegemônica de André, desde a surpresa por ele ter decidido permanecer na companhia de bichas até as minhas indagações com os outros participantes da pesquisa sobre quais seriam os interesses sexuais de André. Comparece, nessa circunstância, uma série de entendimentos sobre desejo e poder contextualizados por uma matriz heteronormativa que orienta nossas práticas sexuais e o uso dos prazeres.

Foi assim que nos submetemos às regras da heteronormatividade masculina falocêntrica compulsória (BUTLER, 2004). André está massivamente preocupado com sua sexualidade, nós, eu, Raul, Camila e Caio estamos também muito preocupados com a sexualidade de André. A surpresa de Camila diante do interesse sexual de André em gays, o questionamento de Caio sobre a possibilidade de André ser bissexual, as nossas expectativas sobre o homem heterossexual com quem íamos ter uma relação sexual, o pavor de André diante da possibilidade de ser exposto, conforme veremos a frente, o questionamento recorrente de André se ele seria gay por transar conosco, são índices que apontam para a vigilância, avaliação e controle da sexualidade (FOUCAULT, 1999), e que, como veremos, incide sobre as práticas de cuidado em saúde sexual.

Chamou atenção, também, a relação que André estabeleceu com o beijo na boca. Primeiramente, ele recusa participar da brincadeira do beijo em que eu, Caio, Raul e Camila, nos envolvemos; depois, ao relatar que transou com uma travesti, dá ênfase ao fato de não tê-la beijado na boca; quando então decide se engajar em uma relação sexual com três bichas, uma das regras impostas por André, é que não teria beijo na boca. A pista linguística "o beijo" indexicaliza ${ }^{21}$ discursos sobre a espacialização/territorialização do desejo e da afetividade. Os significados que André atribui ao papel do beijo na relação com outros homens ou pessoas LGBTI+ têm implicações sobre sua identificação sexual enquanto um homem hétero: não beijar na boca garante a manutenção de sua heterossexualidade masculina.

21. Utilizarei ao longo da análise os termos indexa e indexicaliza como sinônimas. 
Argumento, ainda, que o signo "beijo" indexa discursos de intimidade que são reveladores de uma verdade sobre o desejo. É assim que o ato de "beijar na boca" é perspectivizado por André como incompatível com o comportamento hegemonicamente esperado para um homem heterossexual naquele contexto. A masculinidade hegemônica não permite afetividade, o que constrói, em oposição, um lugar social para corpos travestis e afeminados como relegados à abjeção, ao fetiche e à objetificação.

Nesse sentido, recupero as regras impostas por André sobre a transa que aconteceria entre quatro ${ }^{22}$ pessoas, mas que eram regras impostas pelo homem branco heterossexual ativo sobre nossos corpos gay-afeminados-racializadospassivos. Que significados André articula com as pistas indexicais "não tocar na bunda", "não ter beijo na boca", "que estivéssemos todos juntos"? A "bunda" ou "cu", por exemplo, conforme argumenta Preciado (2009), é o lugar da castração ${ }^{23}$ do homem hétero, por isso lá é o lugar onde não se pode tocar sob pena de violar sua masculinidade hegemônica.

Atento às disputas metapragmáticas no âmbito das performances de gênero/sexualidades por nós encenadas na negociação do sexo na afterparty, foi a experiência na prática sexual que mobilizou uma série de questões que dão relevo às microbiopolíticas de resistências no âmbito do cuidado em saúde.

\subsection{Microbiopolíticas de resistência e cuidado em saúde sexual LGBTI+}

Foi logo após iniciarmos o ritual sexual que:

Com a desculpa de que ia procurar camisinha, saí do quarto, deixando Caio a sós com André. Ao sair, chamei Raul que retornou imediatamente, levando os preservativos.

Do lado de fora, passei algum tempo conversando com Camila (...) [quando] fomos surpreendidos por uma intensa discussão.

Enfurecido, Caio sai do quarto acusando André de ter retirado a camisinha (...) Apontando o dedo para André, Caio afirma que contando um mês a partir dali os dois fariam exames para saber se ele tinha pegado alguma coisa, pois ele sabia de sua própria saúde (...)

Esse momento de tensão extrema mobilizou também uma série de significações sobre cuidado em saúde sexual (...). Nesse sentido, minha intervenção como ativista e pesquisador foi crucial, pois se a condição de vulnerabilidade que se constituía encaminhasse para uma situação de

22. Camila se recusou a participar da relação sexual.

23. Ao contar a história do cu, Preciado explica como o ânus castrado é o armário do heterossexual. O autor destaca que o cu passa a ser uma cicatriz e castrado do prazer, se reduz a um mero excretor de detritos. "Posto a disposição dos poderes públicos, o ânus foi cozido, fechado, selado. Assim nasceu o corpo privado" (2019, p.8). 
contágio, pelo menos no que diz respeito ao HIV, isso poderia ser evitado pelo conhecimento sobre medidas de prevenção, como a testagem e aplicação da PEP24.

Ao perceber que eles desconheciam outras medidas de prevenção ao HIV/aids, flagrantemente a maior preocupação de Caio, intervim e passei a conduzir a situação tentando acalmá-los (...) Expliquei que eu trabalhava com isto e que eu mesmo os levaria a um Centro Especializado. Embora minha expectativa fosse de que eles se acalmassem, a reação de André foi oposta. Ele se desestabilizou completamente e começou a chorar desesperado.

Ele repetia: "o que vou dizer pra minha mãe?", "vou ser descoberto!", "eu sou só um menino", "eu não queria nada disso". Descontrolado, André se apoiava no tanque nos fundos da casa chorando. Caio, completamente revoltado, exige que André se controle para resolvermos a situação juntos como adultos, mas André não conseguia parar de chorar e repetia as mesmas falas.

Depois de algum tempo discutindo, com o dia já amanhecendo, decidimos que iríamos todos a um Centro Especializado. (...) Ao deixá-lo [André] no portão, André lança sua última pergunta antes de seguir. Sério, ele me olha e diz: "mas tu achas eu sou gay por ter transado com vocês?".

Conforme identificamos nessa passagem do caderno de campo, nossas performances narrativas recuperam diferentes instâncias da vida social onde uma biopolítica heterosexista e moralista se organiza. André, ao se desestabilizar revela a preocupação em ser descoberto pela mãe (família). Nenhum dos sujeitos envolvidos na situação conhecia a possibilidade de uso da PEP como medida de prevenção (saúde pública), existente desde 2010 pelo governo federal (FERRAZ; PAIVA, 2015). Eu mesmo só tomei conhecimento quando iniciei esta pesquisa. Estruturalmente desamparados, podemos identificar como microbiopolíticas de resistência tanto o questionamento enérgico de Caio sobre a retirada do preservativo, quanto a condução dos envolvidos a um CE local. As reflexões metapragmáticas geradas ampliam o debate sobre o cuidado em saúde sexual. Atento a essas questões, a narrativa de Caio contada a mim, nos ajuda a aprofundar esse debate analiticamente ${ }^{25}$ :

\section{Excerto 01 - Caio}

01 eu me vejo também como culpado e ao mesmo tempo vítima,

02 assim como o André, também, o garoto heterossexual, de, de Bragança,

24.A Profilaxia Pós-Exposição (PEP) é uma medida de prevenção de urgência à infecção pelo HIV, que consiste no uso de medicamentos para reduzir o risco de adquirir a infecção. Deve ser utilizada após qualquer situação em que exista risco de contágio, tais como: Violência sexual; Relação sexual desprotegida (sem o uso de camisinha ou com rompimento da camisinha); Acidente ocupacional (com instrumentos perfurocortantes ou contato direto com material biológico). Disponível em: http://www.aids.gov.br/pt-br/publico-geral/prevencao-combinada/pep-profilaxia-pos-exposicaoao-hiv Acesso em 06.12.2018.

25. Embora reconheça a relevância indexical de tópicos da oralidade (entonação, alongamento etc.), opto por não fazer tal transcrição por considerar que essa ausência não compromete o enfoque analítico adotado. 
03 ele tem um pouco de, ele tem um pouco de culpa nisso, sem dúvida.

$04 \mathrm{O}$ Raul também, porque estava no ato sexual

05 e não conseguiu ter preocupação com meu corpo.

06 Nem com o corpo do André, nem com o corpo dele. Né.

07 Então ficou assim... e o André também, ele tava, ele tava sem preocupação,

08 porque o André, porque eu tenho certeza que quando alguém tira uma camisinha

09 do teu pau,

10 mano alguém vai, tu vai sentir, saca

11 E de repente eu volto de novo à situação, sem ter percebido, né,

12 pra ser penetrado de novo pelo André, e eu,

13 eu sinto que eu tô, que o André tá sem camisinha.

A performance narrativa de Caio situa o corpo e o cuidado com o outro no centro da sua reflexão. Em busca de encontrar um responsável pela retirada do preservativo, Caio destaca com cores fortes sua angústia, sobretudo pela sua centralidade na situação vivida. Ele estava sendo penetrado e sabia que estava mais vulnerável a adquirir alguma infecção sexualmente transmissível em decorrência disso. Embora sua preocupação fosse com a possibilidade de contrair HIV, ele não se isenta da responsabilidade no cuidado com os corpos envolvidos na situação. O signo "corpo", repetido nas linhas 05 e 06 e o enunciado "não conseguiu ter preocupação" indexam um discurso que projeta uma ampliação no entendimento de cuidado em saúde sexual para além do uso do preservativo ou de medidas técnicas de prevenção, mobilizando importante tópico no âmbito da educação sexual.

A reflexão metapragmática de Caio chama a atenção para a responsabilidade local, entre os sujeitos envolvidos no ato sexual, e para instâncias mais amplas, que nos levam a refletir sobre se e como esses jovens aprendem sobre sexo e saúde sexual nas instituições formativas da vida social, como, por exemplo, a casa e a escola. Em outras palavras, antes de chegar à situação vivida, que discursos e práticas participaram da construção do que seja cuidado em saúde sexual para esses jovens?

As pistas linguísticas "culpa", "culpado", "vítima" além de indexarem discursos sobre a responsabilidade pelo corpo alheio na prática sexual, põem em relevo a questão do não consentimento, no caso do sexo sem preservativo. Por outro lado, é possível interpretar que essa forte preocupação também aponta para a noção patologizante e o sentido de perigo agregado às práticas sexuais sem preservativo, sobretudo no contexto gay. Conforme comparece em outros dados da pesquisa (SENA, 2020a) foi flagrante a diferença na preocupação com o uso do preservativo entre mulheres cisheterossexuais e homens gays, em que as primeiras estavam massivamente preocupadas com a gravidez, e os últimos com o HIV. Considero, 
nesse aspecto, que a falta de informação sobre outras medidas de prevenção, como a PEP, ajuda na intensificação do tensionamento vivido. Comparece ainda a diferença entre o peso que tem transar sem preservativo no contexto LGBTI+, sobretudo gay, e no contexto heterossexual, o que ratifica a LGBTfobia estrutural.

Além disso, chamo atenção para o caráter proibido e não negociado, em termos de cuidado, da prática sexual. A transa ocorreu em um quarto escuro onde não vimos o pênis de André, onde não conseguíamos ver nossos corpos. Em momento algum conversamos sobre como se daria aquela relação, sendo as únicas regras as impostas por André sobre sua heterossexualidade. Argumento que essa dificuldade em estabelecer um diálogo mais franco para essa experiência sexual decorre precisamente das normatizações que nos cerceiam enquanto LGBTI+ e $\mathrm{HSH}$, nos coagindo a esse lugar da falta de diálogo e atenção com o outro, e que também ratificam o tabu, muito presente no discurso moral de diferentes instituições religiosas sobre o sexo fora das práticas sexuais reprodutivas.

Ao longo dos diálogos na pesquisa de campo, emergiu também a suspeita da retirada do preservativo de modo proposital por parte do André. Compareceram ao longo do estudo (SENA, 2020a) situações de retirada do preservativo sem consentimento por homens em relações heterossexuais. Essa suspeita é apontada na narrativa de Caio nas linhas 08 e 09 "porque eu tenho certeza que quando alguém tira uma camisinha do teu pau", "tu vai sentir". As pistas linguísticas "certeza", "vai sentir" e "sem preocupação" (linha 07) constroem indexicalmente a interpretação de Caio sobre a pouca importância que André deu à relação sem preservativo recuperando, assim, discursos mais amplos do comportamento heterossexual sobre sexo sem camisinha.

Diante das narrativas de Caio, é importante recuperar das notas de campo os modos como esses sujeitos constroem suas práticas de cuidado em saúde, que têm um ponto de culminância/tensionamento na experiência aqui descrita. No que diz respeito a Raul, a mim e a Caio, o discurso do uso do preservativo, embora presente em algum momento de nossas trajetórias, e construtor de um tipo de noção de cuidado e prevenção, é desarticulado pela homofobia familiar velada. Embora os três tenham sido aceitos em casa a partir de algum momento das trajetórias pessoais como gays, o medo, a insegurança e a falta de apoio acompanharam essas subjetividades nas suas construções enquanto sujeitos da saúde sexual. Essa reflexão, inclusive, vai ao encontro das narrativas de outros sujeitos da pesquisa (SENA, 2018; 2020a).

Destaco, ainda, que essas demandas se agravam contra sujeitos LGBTI+ em outras conjunturas mais extremas, como os que se encontram em situação de 
pobreza e em contextos sociais de acesso restrito à informação e educação, como os que vivem, por exemplo, em zonas rurais da região.

Ao considerarmos os preconceitos, dilemas e microviolências vividas cotidianamente por pessoas LGBTI+, e que são fortemente contrastados com a forma legítima e moralmente aceita com que as práticas sexuais heteronormativas são recebidas, chegamos às condições estruturais que vulnerabilizam nossos corpos dissidentes, uma LGBTfobia estrutural e talvez até uma necropolítica sistemática e institucional. Conforme argumentei ao longo do texto, esse silenciamento sobre nossos modos de vida dissidentes, produzido por meio de constrangimentos e deslegitimação de nossas subjetividades, repetições diárias e naturalizadas, pode ser considerada uma política de morte contra "corpos que não importam".

Faço esta reflexão, pois quando chegamos à subjetividade de André, forjado no padrão heterossexual, cisgênero, numa cidade média da Amazônia Atlântica, e castrado da possibilidade de viver seus desejos sexuais dissidentes, como nas relações com outros homens, o peso da homofobia recai com outro tipo de força. Ao ocupar um lugar de poder, sendo vítima e opressor desse regime hegemônico do gênero/sexualidade, André se torna um grave problema para ele mesmo e para os sujeitos LGBTI+ com quem se envolve. Há dois discursos produzidos por e sobre André: o discurso do homem e o discurso do menino, discursos que podem ser associados ao gênero, à sexualidade e à idade/experiência. Estamos diante agora de um discurso que fala sobre André em termos de cuidado sexual ou a ausência dele.

Excerto 02 - Caio

14 Porque eu me cuido, e isso é muito foda

15 a gente cuidar do nosso corpo pra vim outra pessoa

16 e a gente dá permissão da outra pessoa tocar nosso corpo

17 da gente interagir com ela, e a pessoa não consegue se ligar

18 que ela tem que ter responsabilidade com o corpo dela e com o meu corpo.

19 Então eu berro tudo isso, que eu tenho responsabilidade com meu corpo,

20 que eu quero respeito com meu corpo,

21 e agora se eu tiver alguma coisa o que eu vou fazer daqui pra frente,

22 vou ter que fazer exame, saca, vou ter que viver com isso.

Caio se posiciona como alguém que cuida de sua saúde, conforme apontam os índices linguísticos "eu meu cuido", "eu tenho responsabilidade com o meu corpo", se referindo aqui ao uso de preservativo e à testagem, conforme recupero das notas de campo. Entretanto, chama novamente atenção para a dimensão do cuidado que enfatiza as relações humanas, conforme indexam as pistas linguísticas 
"responsabilidade", "com o corpo dela" e "com o meu corpo" (linha 18). A performance narrativa de Caio, e suas reflexões em torno do aspecto humano do cuidado, e que reverberam as experiências narradas por outros sujeitos da pesquisa dá relevo às consequências da ausência ou precariedade de educação sexual, a ausência de diálogo franco e aberto com os jovens sobre sexualidade, saúde sexual, sobre fazer sexo, pois a carência de informação combinada com a falta de diálogo gera, além de um regime de medo e insegurança, o reforço de preconceitos e estigmas sobre sexualidades subalternas, condições de vulnerabilidade.

Diante dessa disputa de entendimentos, Caio sublinha a condição homofóbica e opressora que envolve as vidas tanto das pessoas heteronormativas quanto das dissidentes. Em seguida destaca mais um aspecto que se impõe sobre o cuidado em saúde de pessoas LGBTI+:

\section{Excerto 03 - Caio}

23 esse macho que oprime as bicha, quando passa na rua,

24 quando chega numa situação dessa se desmancha,

25 porque ele não dá conta de arcar com o peso psicológico

26 que isso pode ter uma doença sexualmente transmissível,

27 e mais que isso também, sabe,

28 que agora que eu vejo que tem a parte da saúde psicológica

29 que é como a gente fica, depois de tudo isso, sabe

30 Transe com quem você quiser, mas não foda ninguém, saca?

$31 \mathrm{E}$ foi isso que aconteceu, ele transou

32 mas a merda toda é que ele fudeu com as nossas cabeças.

A performance narrativa de Caio inicialmente opõe as pistas indexicais "macho" e "bicha", projetando a relação de discursos de poder e abjeção do primeiro em relação ao segundo. Uma análise mais escrupulosa, no entanto, permite projetar um entendimento de que o binarismo entre essas subjetividades se desfaz diante de situações graves como a vivência de uma situação de vulnerabilidade. O índice linguístico "desmancha" (linha 24) produz indexicalmente a dicotomia força/fragilidade que acompanha as compreensões sobre masculinidades tóxicas. Do macho ao menino, a mudança de contexto altera a posição do sujeito e seu potencial semiótico de significação. Desse modo, argumento com Saldanha et al. (2008) que é necessário "ampliar o debate em torno dos modelos de masculinidade e feminilidade culturalmente construídos" e seus efeitos no âmbito da saúde sexual (SALDANHA et al. 2008, p. 36).

O que se observa nos dados analisados é a interseção gênero-sexualidadesaúde sexual. Dentro do conjunto dos discursos sobre a saúde sexual, é possível 
identificar, de forma mais específica, a saúde psicológica, como vimos no Excerto 03, performado por Caio. A narrativa de Caio também produz uma reflexão sobre a dimensão psicológica do cuidado em saúde sexual, em que os enunciados "como a gente fica depois", "não foda ninguém" e "fudeu com as nossas cabeças" indexam os sentidos de saúde sexual que extrapolam as medidas de prevenção e cuidado restritas à distribuição de preservativo ou da prática da testagem, por exemplo. Por fim, Caio mobiliza sentidos de vigilância e policiamento de práticas sexuais em sua performance narrativa:

Excerto 04 - Caio

33 porque a cidade não é tão grande, né, muitas pessoas se conhecem.

34 Então ele não queria ser reconhecido.

35 Mas ele não quer ser reconbecido por estar fazendo exame de HIV? Né,

36 de uma doença sexualmente transmissível,

37 ou ele não queria ser reconbecido pordue ele tava com uma gay?

38 Quer dizer que nesse momento a minha condição sexual, né,

39 é menos, e menos do que (inaud.) é uma coisa que não merece atenção.

40 Aaaa a imagem dele como heterossexual é muito mais importante

41 do que, do que a minha saúde sexual?

42 Ele prefere manter um nome a um corpo saudável?

43 E o corpo com quem transou com ele?

Os enunciados "a cidade não é tão grande" e "muitas pessoas se conhecem" indexam sentidos de microvigilância sobre as práticas de cuidado em saúde sexual, sobre quem acessa, por exemplo, o CTA na cidade, recuperando também a reflexão de outros sujeitos envolvidos no estudo. Entretanto, em um alto nível de reflexividade metapragmática, Caio mobiliza índices que ajudam a construir os sentidos sobre como a heteronormatividade compulsória pode comprometer práticas de cuidado em saúde, radicalizando significados e efeitos dos binarismos de gênero/sexualidades sobre a saúde. Ao questionar o motivo pelo qual André não queria ser reconhecido, Caio mobiliza, com os enunciados "por estar fazendo exame de HIV" e "porque ele tava com uma gay", entendimentos sobre o alto nível de coerção das normas de gênero/sexualidades sobre André.

A performance narrativa de Caio aprofunda, por fim, a reflexão sobre o peso da coerção social de policiamento do sexo-gênero, da matriz heterossexual falocêntrica masculina sobre André e sobre a relação humana em causa, onde estavam implicados domínios do prazer e da saúde, conforme indexicalizam os enunciados nas linhas 40 "a imagem dele como heterossexual é muito mais importante" e 42 "ele prefere manter um nome a um corpo saudável". 


\section{(META)PRAGMÁTICAS DE RESISTÊNCIA}

Criando condições de enunciação para corpos dissidentes desde a Amazônia Atlântica, o estudo traz ganhos importantes para o debate sobre como regimes biopolíticos cisheteronormativos têm silenciado e precarizado modos de vida LGBTI+, especialmente no âmbito das práticas de cuidado em saúde sexual, o que envolve estruturalmente a família, a escola e a saúde pública. Resistindo a tal regime, microbiopolíticas de resistência têm se erguido, e mesmo que se constituído em movimentos microcapilares ou em situações extremas vividas, como as analisadas, esse processo é denso e se estende desde as formas de existir como pessoa LGBTI+, e o confronto as LGBTfobias diárias, até o cuidado em saúde sexual.

Olhar/agir nesse processo como um pesquisador radicalmente in-mundo tem/ teve efeitos políticos situados entre os sujeitos LGBTI+ localmente, mas também potencializa essa aposta Contra-colonial e Indisciplinar em que a linguagem assume protagonismo na produção de resistência (SENA, 2020b). Argumento, por fim, que esta pesquisa e este texto também constituem essa engrenagem microbiopolítica que aposta na resistência e nas políticas de existência dos corpos dissidentes, especialmente diante dos ataques sofridos pela frágil democracia brasileira na sua atual gestão política e a agenda bio-necropolítica que agencia.

\section{REFERÊNCIAS}

ALENCAR, L. (2014) No rastro dos "pés descalços": da Marujada à narrativa literária. Dissertação de Mestrado em Linguagens e Saberes na Amazônia, Universidade Federal do Pará, Bragança.

ABRAÃO, A.; MERHY, E.; GOMES, M.; TALLEMBERG, C.; CHAGAS, M.; ROCHA, M.; SANTOS, N.; SILVA, E.; VIANNA, L. (2013) O pesquisador in-mundo e o processo de produção de outras formas de investigação em saúde. Revista Lugar Comum, p.133-144.

AUSTIN, J. (1990) Quando dizer éfazer. Palavras e Ação. Tradução de Danilo Marcondes de Souza Filho. Porto Alegre: Artes Médicas.

AYRES, R.; PAIVA, V.; FRANÇA JR, I. (2012) Conceitos e Práticas de prevenção: da história natural da doença ao quadro da vulnerabilidade e direitos humanos. In: AYRES; PAIVA; BUCHALLA (Org.) Vulnerabilidade e direitos bumanos: prevenção e promoção da saúde: da doença a cidadania. Curitiba: Juruá Editora, p.71-94. 
BAUMAN, R. ; BRIGGS, C. (2003) Voices of modernity: language ideologies and the politics of inequality. Cambridge: Cambridge University Press.

BENTO, B. Apresentação. In: COLLING, L. Que os outros sejam o normal: tensões entre movimento LGBT e ativismo queer [online]. Salvador: EDUFBA, 2015, p. 13-19.

BRASIL. (2013) Ministério da Saúde. Secretaria de Gestão Estratégica e Participativa. Departamento de Apoio à Gestão Participativa. Política Nacional de Saúde Integral de Lésbicas, Gays, Bissexuais, Travestis e Transexuais / Ministério da Saúde, Secretaria de Gestão Estratégica e Participativa, Departamento de Apoio à Gestão Participativa. Brasília: 1. ed., 1. reimp. Ministério da Saúde.

BRASIL. (2015) Ministério da Saúde. Secretaria de Gestão Estratégica e Participativa. Departamento de Apoio à Gestão Participativa. Relatório do Seminário Nacional de Saúde LGBT, I / Ministério da Saúde, Secretaria de Gestão Estratégica e Participativa, Departamento de Apoio à Gestão Participativa - Brasília: Ministério da Saúde.

BRASIL. (2019) Ministério da Saúde. Secretaria de Vigilância em Saúde - Departamento de DST, Aids e Hepatites Virais. Boletim epidemiológico HIV/Aids: jan./jun. 2018. Secretaria de Vigilância em Saúde - Departamento de DST, Aids e Hepatites Virais.

BRITO, J. SARAIVA, J. SILVA, J. (2019) Região de integração do rio caeté: uma visão socioeconômica e histórico-cultural do município de Bragança-PA. Revista GeoAmazônia Belém v. 07, n. 13 p. 168-182.

BUTLER, J. (2004) Problemas de Gênero: feminismo e subversão da identidade. Trad. Renato Aguair. Rio de Janeiro: Civilização Brasileira.

CALAZANS, G. PINHEIRO, T. AYRES, J. (2018) Vulnerabilidade programática e cuidado público: Panorama das políticas de prevenção do hiv e da Aids voltadas para gays e outros hsh no Brasil. Sexualidad, Salud y Sociedad Revista Latinoamericana, n. 29 - ago. p.263-293.

CLIFFORD, J. (2002) A experiência etnográfica: antropologia e literatura no século XX/ James Clifford; organizado por José Reginaldo Santos Gonçalves. 2. ed. Rio de Janeiro: Editora UFRJ.

CONNELL, R.; MESSERSCHMIDT, J. Masculinidade hegemônica: repensando o conceito. Estudos Feministas, Florianópolis, 21 (1): 241-282, janeiro-abril, 2013

CORDEIRO, I. ARBAGE, M. SCHUWARTZ, G. (2017) Nordeste Paraense: Configuração Atual e Aspectos Identitários. In: CORDEIRO, I. et al (Orgs.) Nordeste Paraense: 
Panorama geral e uso sustentável das florestas secundárias. Belém, PA: EDUFRA, p.19-58.

DERRIDA, J. (1991) Margens da Filosofia. Campinas - SP: Papirus.

DERRIDA, J. (1973) Gramatologia. São Paulo, Perspectiva, Ed. da Universidade de São Paulo.

FABRÍCIO, B. (2006) Linguística Aplicada como espaço de desaprendizagem: redescrições em curso. In: Luiz Paulo da Moita Lopes. (Org.). Por uma lingüística aplicada INdisciplinar. São Paulo: Parábola Editorial, p. 45-65.

FERRAZ, D. PAIVA, V. (2015) Sexo, direitos humanos e AIDS: uma análise das novas tecnologias de prevenção do HIV no contexto brasileiro. Revista Brasileira de Epidemiologia. n.18.v.1, p.89-103.

FOUCAULT, M. (1999) História da Sexualidade I: A vontade de saber. 13. ed. Rio de Janeiro: Graal.

FOUCAULT, Michel. (2008) Segurança, território, população. Tradução de E. Brandão. São Paulo: Martins Fontes.

FOUCAULT, Michel. (2000) Em defesa da sociedade: curso no College de France. Tradução de Maria Ermatina Galvão. São Paulo: Martins Fontes.

HYDEN, L. HYDÉN, M. HARRISON, B. ANDREWS, M. ESIN, C. DAVIS, M. SQUIRE, C. (2014) The uses of narrative research. In: Hydén, Lars-Christer et al. What is narrative research? Londres: Bloomsbury Academic, p.73-93.

JUNG, N. SILVA, R. SANTOS, M. (2019) Etnografia da linguagem como políticas em ação. Calidoscópio 17(1): 145-162.

LIMA, F. (2018) Bio-necropolítica: diálogos entre Michel Foucault e AchilleMbembe. Arquivos Brasileiros de Psicologia. Rio de Janeiro, 70 (no.spe.), p.20-33.

MARTINS, H. (2004) Três caminhos da Filosofia da linguagem. In: MUSSALIM, F.; BENTES, A. Introdução à linguística: fundamentos epistemológicos. São Paulo: Cortez, vol. 3, p. 439-473.

MELO, G.; MOITA LOPES, L. P. (2014) Ordens de indexicalidade mobilizadas nas performances discursivas de um garoto de programa: ser negro e homoerótico. Linguagem em (Dis)curso - Tubarão, SC, v. 14, n. 3, p.653-673. 
MOITA LOPES, L. P. (2006) Por uma Linguística Aplicada Indisciplinar. Parábola Editorial: São Paulo, 2006.

MOITA-LOPES, L. P.; FABRICIO, B. (2019) Por uma proximidade crítica nos estudos em Linguística Aplicada. Calidoscópio, v. 17, p. 711-723.

MORA, C.; BRIGEIRO, M.; MONTEIRO, S. (2018) A testagem do HIV entre "HSH": tecnologias de prevenção, moralidade sexual e autovigilância sorológica. Physis: Revista de Saúde Coletiva, Rio de Janeiro, v. 28(2), p.1-28.

PEIRANO, M. (2014) Etnografia não é método. Horizontes Antropológicos, Porto Alegre, ano 20, n. 42, p. 377-391.

PEIRANO, M. (2008) Etnografia, ou a teoria vivida. Ponto.Urbe (USP), v. vol. 2, versao 2.0.

PERUZZO, C. (2017) Pressupostos epistemológicos e metodológicos da pesquisa participativa: da observação participante à pesquisa-ação. Esdios sobre lãs culturas contempoáneas. Épocsa III. Vol. XXIII. Numero Especial III, Colina, primavera, p.161-190.

PRECIADO, P. (2019) Terror Anal: notas sobre os primeiros dias da revolução anal. Trad. De Inaê Diana Ashokasundari Shravya. Imprensa Marginal: Rio de Janeiro.

PRECIADO, P. (2018) Texto Junkie: sexo, drogas e biopolítica na era farmacopornográfica. São Paulo: n-1.

RAFFESTIN, C. (1993) Por uma geografia do poder. São Paulo: editora ática.

REIS, A.; SANTOS, E.; CRUZ, M. (2007) A mortalidade por aids no Brasil: um estudo exploratório de sua evolução temporal. Epidemiol. Serv. Saúde, Brasília, 16(3), p.195-205.

SALDANHA, A.; CARVALHO, E.; DINIZ, R.; FREITAS, E.; FÉLIX, S, SILVA, E. (2008) Comportamento sexual e vulnerabilidade à aids. DST - Jornal brasileiro de doenças sexualmente transmissíveis, 20(1), p.36-44.

SANTOS, A. B. (2015) Colonização, Quilombos: modos e significados. Brasília.

SENA, J. (2020a) Corpos Dissidentes e Biopolítica na Amazônia Atlântica: disputas metapragmáticas no cuidado em saúde. Tese de Doutorado em Linguística Aplicada, Universidade Federal do Rio de Janeiro, Rio de Janeiro.

SENA, J. (2020b) O protagonismo da linguagem na produção de corpos, discursos e práticas de resistência. Percursos Linguísticos. v. 10 n. 25, p.123-143. 
SENA, J. (2018) Masculinidades e Práticas Sexuais na Amazônia Oriental: notas de campo com base em uma experiência etnográfica. In: CAETANO, M.; MELGAÇO, P. De Guri a Cabra Macbo: masculinidades no Brasil. Lamparina: Rio de Janeiro, p.107-125.

SÍCOLI, J.; NASCIMENTO, P. (2003) Health promotion: concepts, principlesandpractice, Interface - Comunic, Saúde, Educ, v.7, n.12, p.91-112.

SILVA, D. (2014) O texto entre a entextualização e a etnografia: um programa jornalístico sobre belezas subalternas e suas múltiplas recontextualizações. Linguagem em (Dis)curso (Impresso), v. 14, p. 67-84.

SILVERSTEIN, M. (1998) The uses andutilityofideology: a commentary. In: SCHIEFFELIN, B. ; WOOLARD,K. A.; KROSKRITY, P. Language Ideologies: Practice and theory. Oxford. OUP, p. 123-148.

SILVERSTEIN, M. (2003) Indexical order and the dialectics of sociolinguistic life. Language \& Communication, 23, p.193-229.

LAURINDO-TEODORESCU, L.; TEIXEIRA, P. (2015) Histórias da aids no Brasil: as respostas governamentais à epidemia de aids. Brasília: Ministério da Saúde/Secretaria de Vigilância em Saúde/Departamento de DST, Aids e Hepatites Virais.

WORTHAM, S. (2001) Narratives in action. A strategy for research and analysis. Teachers College: Columbia University.

Recebido: 16/9/2020

Aceito: 18/11/2020

Publicado: 23/11/2020 